\title{
Surgical Pathology of Non-Neoplastic Lung Disease
}

Thomas V. Colby, M.D.

Department of Laboratory Medicine and Pathology, Mayo Clinic Scottsdale, Scottsdale, Arizona

At inception, this course included some neoplastic lesions, but each year, the case mix was changed in response to the comments (and criticism) of the attendees. As cases were added and deleted, in the end only examples of non-neoplastic lung disease were discussed. Of the 19 cases used during the course of 5 years, the following 8 were selected for this presentation.

\section{CASES 1, 2, AND 3: IDIOPATHIC INTERSTITIAL PNEUMONIAS AND RELATED LESIONS}

To the clinician, there are well over 100 causes of interstitial pneumonia, but among these, there is a select subgroup that has been called the idiopathic interstitial pneumonias. This group has evolved from Liebow and Carrington's (1) classic classification of chronic interstitial pneumonias:

Usual interstitial pneumonia (UIP)

Desquamative interstitial pneumonia (DIP)

Bronchiolitis obliterans with interstitial pneumonia

Giant cell interstitial pneumonia

Lymphoid/lymphocytic interstitial pneumonia

The most current iteration of the classification of the idiopathic interstitial pneumonias is that of Katzenstein and Myers (2):

Acute interstitial pneumonia

UIP

DIP

Nonspecific interstitial pneumonia (NSIP)

For the most part, the idiopathic interstitial pneumonias require a surgical lung biopsy to recognize the pattern and make the diagnosis. Transbronchial biopsies in these cases are usually abnormal, but the findings are nonspecific and rarely diagnostic. The following three cases illustrate some of the variants of the idiopathic interstitial pneumonias and related lesions that are now recognized.

Copyright (C) 2000 by The United States and Canadian Academy of Pathology, Inc.

VOL. 13, NO. 3, P. 343, 2000 Printed in the U.S.A

Date of acceptance: October 26, 1999.

Address reprint requests to: Thomas V. Colby, M.D., Mayo Clinic, 13400

East Shea Boulevard, Scottsdale, AZ 85259; fax: 480-301-8372.
Case 1: Acute Exacerbation of Idiopathic Pulmonary Fibrosis

A 51-year-old man had experienced 3 to 4 years of progressive dyspnea and interstitial infiltrates as observed on chest radiographs. One week before death, there was acute worsening of his dyspnea, with some associated chills and a sore throat. At admission, he was hypoxemic, tachypneic, and afebrile. The clinical impression was an acute (possibly infectious) process superimposed on idiopathic pulmonary fibrosis (IPF). An open-lung biopsy was performed. The patient died 1 week later. Cultures and special stains were negative.

\section{Histologic findings}

The open biopsy shows subpleural scarring and microscopic honeycombing, with associated smooth muscle metaplasia and fibroblastic foci (Figs. 1 and 2). Away from the subpleural regions in the architecturally preserved lung parenchyma, there is acute and organizing diffuse alveolar damage (DAD), hyaline membranes, type 2 cell metaplasia, and interstitial edema with a scant inflammatory infiltrate (Fig. 2). The histologic appearance is acute, and organizing DAD is superimposed on a background fibrotic process that shows the typical subpleural and paraseptal fibrosis of usual interstitial pneumonia.

\section{Discussion}

$I P F$ is the term favored by clinicians in North America for the classic form of progressive pulmonary fibrosis that has been called cryptogenic fibrosing alveolitis in England (2-4). UIP was initially a term used to designate a pattern (e.g., UIP caused by asbestos, UIP caused by drug reaction) (1), but eventually, after the series of Carrington et al. in the New England Journal of Medicine in 1978 (5), UIP became recognized as a specific pattern of chronic interstitial pneumonia synonymous with IPF (2-4). DIP is no longer included among cases of IPF, and it is separate and distinct from UIP (2-4).

IPF is a distinct clinicopathologic entity and does not include every case of interstitial lung disease with interstitial fibrosis (2-6). The vast majority of patients with IPF present after age 50, and males are affected more often than females. Affected pa- 

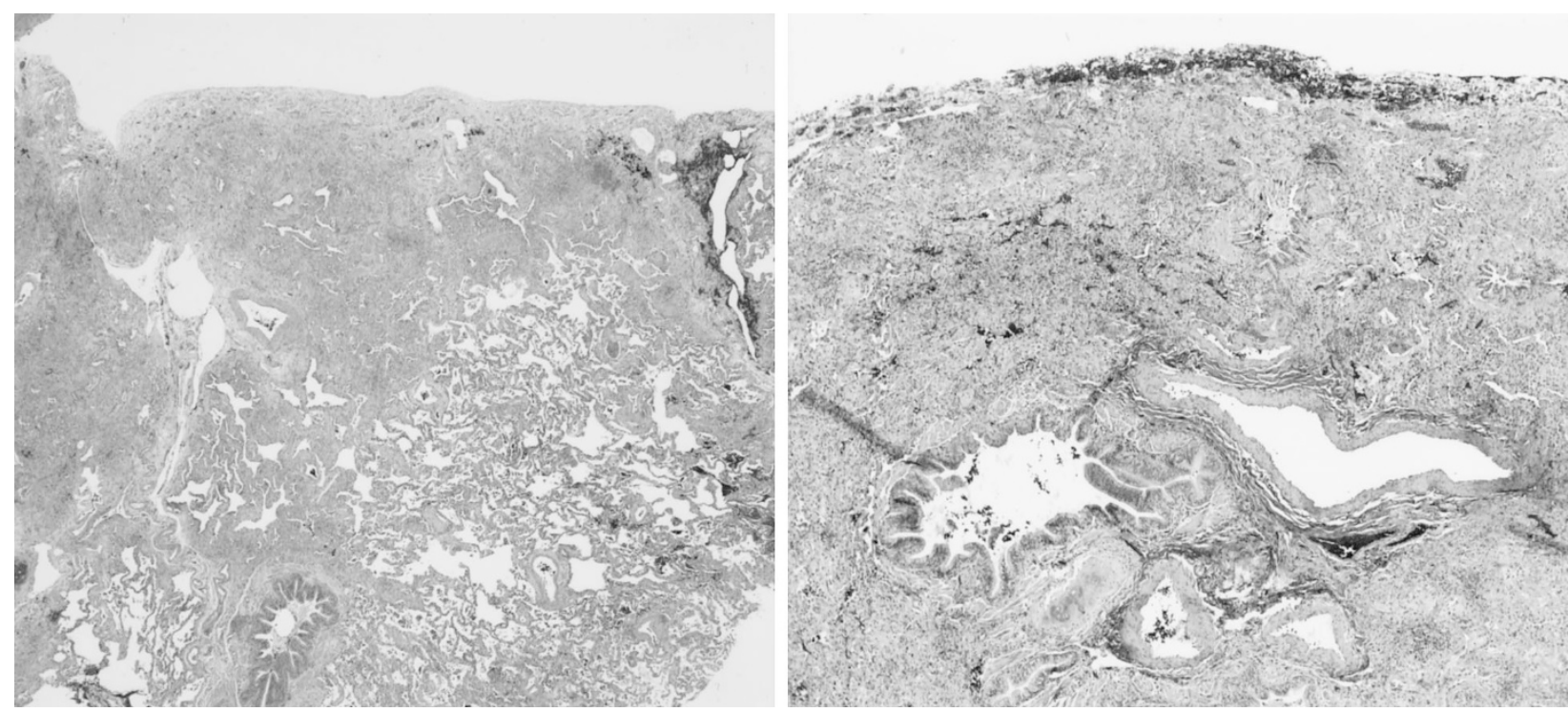

FIGURE 1. Acute exacerbation of IPF. Scanning power microscopy showing patchy involvement of the lung parenchyma (left) with zones of subpleural scarring and loss of alveoli (upper left) and zones where lobules have completely dropped out (right), where a small bronchus (lower center) is in close apposition to the pleural surface (top) with intervening, architecturally destroyed lung tissue containing a small bronchiole (upper right center).
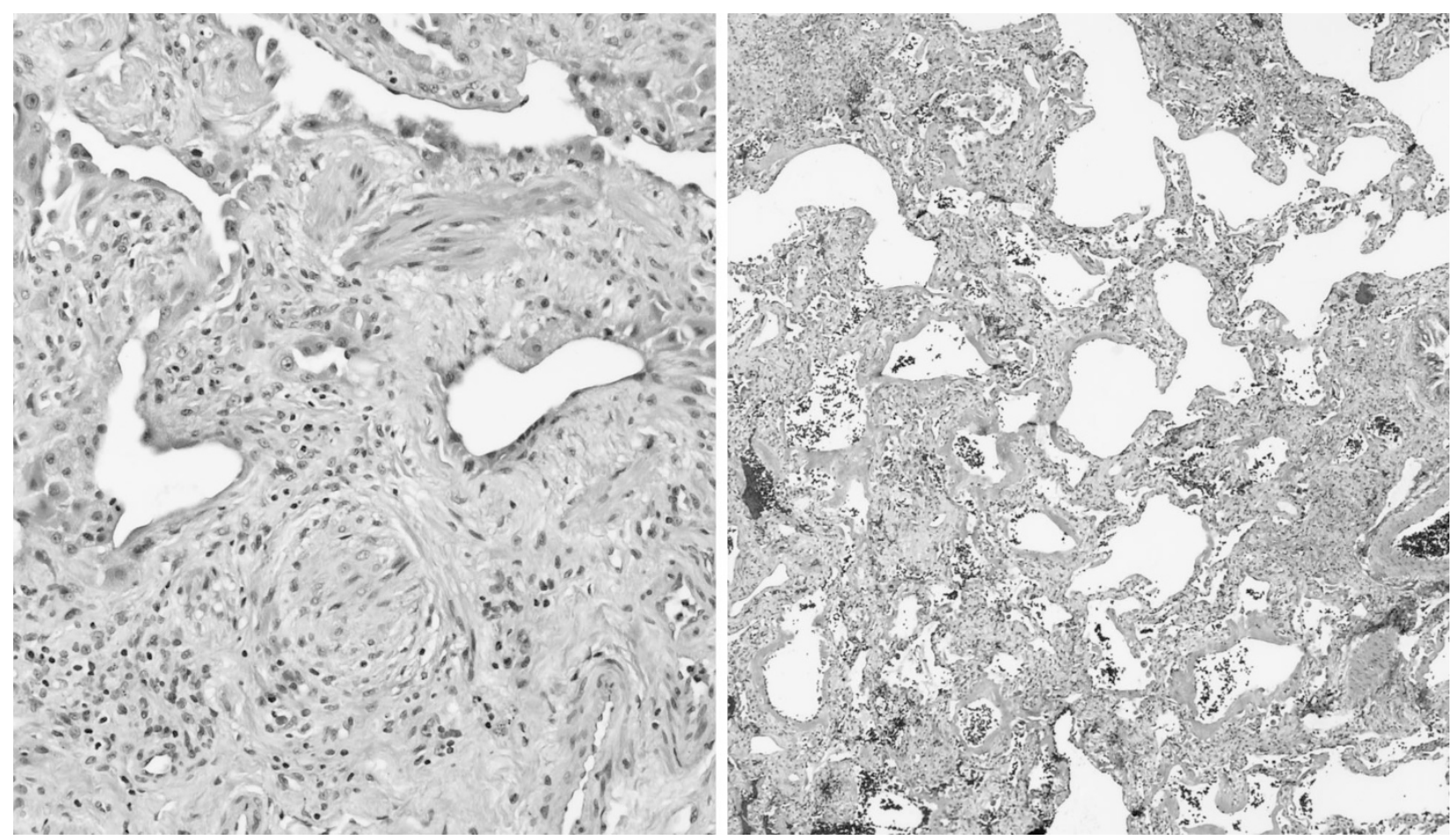

FIGURE 2. Acute exacerbation of IPF. In the zones of chronic fibrosis (left), one can see distortion of alveoli and interstitial smooth muscle metaplasia (left, upper center) adjacent to rounded foci of fibroblastic proliferation (left, lower center). In the architecturally intact alveoli, there is acute diffuse alveolar damage with hyaline membranes lining alveoli that have septal edema (right).

tients have insidiously progressive dyspnea and bilateral lower lobe interstitial infiltrates on the chest radiograph, usually with peripheral honeycombing identified on high-resolution computed tomographic scans. The median survival after diagnosis is 3 to 5 years. The causes of death in patients with IPF include respiratory insufficiency (39\%), heart failure $(14 \%)$, carcinoma of the lung $(10 \%)$, stroke $(10 \%)$, and other intercurrent diseases (7).
Fulminant respiratory failure is a common cause of death in patients with IPF, and most cases represent acute exacerbation of IPF (8-12). Typically, a patient who is being followed for interstitial lung disease develops acute respiratory failure, often accompanied by fever, elevation of the sedimentation rate, marked increase in dyspnea, and new radiographic infiltrates that often have an alveolar character. For many years, this was thought to be a 
superimposed infection, but because organisms are rarely identified and a small percentage of patients respond to pulse steroids, a number of investigators consider this syndrome a fulminant progression of the disease process itself $(8,9,11,12)$. Overall, this condition has a poor prognosis, and death within 1 week, as in the case of the patient presented, is not unusual (8). Histologically, DAD (acute or organizing) is superimposed on the background UIP (9, 12).

Typical interstitial pneumonia and DAD are usually considered separate entities, which is true for the most part. Recent ultrastructural and immunohistochemical evidence, however, suggests that the basic process of lung injury and repair is similar in these two conditions (13), and it is not surprising that DAD might represent the morphologic manifestation of the fulminant progression of UIP.

UIP shows patchy interstitial fibrosis, honeycombing, and temporal homogeneity-old scarring associated with more active fibroblastic foci $(2,4,6$, 9 ). These features are more difficult to appreciate when DAD is superimposed, as fibroblastic foci may be similar to foci in organizing DAD.

$\mathrm{DAD}$, a common reaction pattern, is a generally diffuse and temporally uniform process that, in biopsy material, may show an acute exudative phase (with hyaline membranes), as well as an organizing phase with type 2 cell metaplasia, interstitial thickening and edema, and variable amounts of airspace and interstitial fibroblastic proliferation (14). Common causes of DAD include infections, toxic inhalations/ingestions, drug reactions, shock, collagen vascular diseases, acute radiation reaction, acute allergic reactions, and idiopathic acute interstitial pneumonia.

\section{Case 2: Smoking-Related Interstitial Lung \\ Disease with Features of Respiratory \\ Bronchiolitis Interstitial Lung Disease and DIP \\ History}

A 37-year-old woman with a 20 pack-year smoking history was being followed for increasing cough and dyspnea, bilateral pulmonary infiltrates observed on chest radiographs, and decreasing diffusing capacity. A nodule was noted, and a lobectomy was performed. The nodule was a well-differentiated adenocarcinoma. The sections are from the surrounding lung.

\section{Histologic findings}

The lung tissue shows mild interstitial thickening and inflammation (Fig. 3). Honeycombing is not present. The airspaces show prominent filling, with pigmented alveolar macrophages (typical of those seen in smokers). In some regions, these cluster
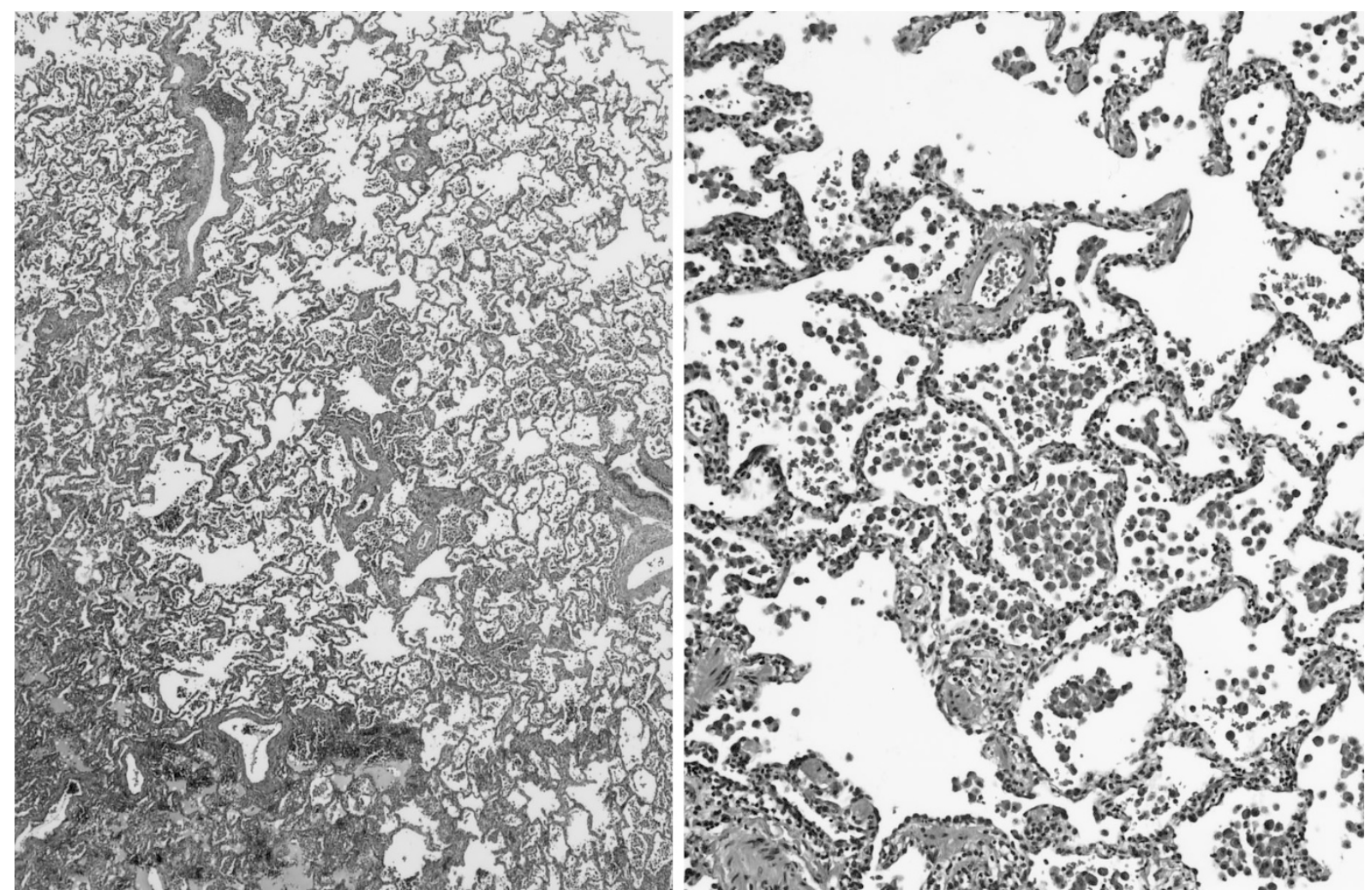

FIGURE 3. Smoking-related interstitial lung disease (DIP/RBILD). There is relatively uniform involvement of the lung parenchyma, which does not show loss of architecture or significant fibrosis $($ left). In some regions, there is a predilection for the increase in alveolar macrophages to be around respiratory bronchioles (left, center). Higher power microscopy shows features of desquamative interstitial pneumonia, with marked increase in alveolar macrophages and mild increase in interstitial cellularity and alveolar septal widening (right). 
around respiratory bronchioles (respiratory bronchiolitis), whereas elsewhere, they diffusely involve the lung parenchyma (Fig. 3). S-100 stains showed no evidence of Langerhans' cell histiocytosis.

\section{Discussion}

Virtually all cigarette smokers develop an inflammatory reaction around respiratory bronchioles called "respiratory bronchiolitis" (15). This is usually an incidental histologic finding in the lung tissue; terminal airways, particularly respiratory bronchioles, and alveolar ducts show mild interstitial fibrosis and inflammation in the walls, type 2 cell metaplasia in the surrounding alveoli, and prominent filling of airspaces (including alveoli around the bronchiole) by pigmented macrophages. Another term for this reaction is "smoker's bronchiolitis."

In a small percentage of smokers, respiratory bronchiolitis becomes much more extensive and causes signs and symptoms (cough and dyspnea), functional findings (restriction and decreased diffusing capacity), or radiologic findings (bilateral pulmonary infiltrates or ground glass change) of interstitial lung disease, which is called respiratory bronchiolitis interstitial lung disease (RBILD)(1618). Most affected patients are between 25 and 55 years of age, and all (by definition) are smokers. In one series of RBILD, some of the cases were culled from previous series of DIP (18).

Where does the recognition of RBILD leave DIP? The vast majority (over 90\%) of patients with DIP are smokers (5), and the distinction between DIP (which in theory is a uniformly diffuse process) and RBILD (a patchy process restricted to respiratory bronchioles) is difficult, because fields showing features of both are often found in the same case. The overlap between RBILD and DIP is illustrated by the case under discussion, and most cases in these categories are part of a RBILD/DIP spectrum of smoking-related interstitial lung disease. There are rare cases of DIP that occur in nonsmokers.

Lesions/diseases associated with smoking now include

1. Chronic obstructive pulmonary disease (chronic bronchitis/emphysema)

2. Carcinoma of the lung

3. Respiratory bronchiolitis

4. RBILD

5. DIP

6. Pulmonary Langerhans' cell histiocytosis (pulmonary histiocytosis X)-most patients are smokers, and some have remission of the disease after cessation of smoking

7. Usual interstitial pneumonia/idiopathic pulmonary fibrosis (smoking is an epidemiologically identified risk factor [19])
While a pure pattern resembling DIP is rarely seen outside the setting of the RBILD/DIP spectrum, there are a number of conditions in which foci resembling DIP may be present to a greater or lesser extent:

DIP/RBILD

Langerhans' cell histiocytosis

Drug reactions (especially amiodarone)

Chronic alveolar hemorrhage

Eosinophilic pneumonia

Pneumonoconioses (especially talcosis, hard metal, asbestosis)

Obstructive pneumonias

Exogenous lipoid pneumonias

Lipid storage diseases

Histiocyte-rich pneumonias in the immunosuppressed setting

As a focal histologic finding very commonly

\section{Case 3: NSIP}

A 53-year-old woman presented with a severalmonth history of increasing shortness of breath. A chest radiograph showed bilateral interstitial infiltrates, and computed tomographic scans showed infiltrates more prominent in the lower lobes, without peripheral honeycombing. The patient had no clubbing and no crackles on auscultation. Openlung biopsy was performed. The patient was placed on steroid therapy, and her cough improved. The chest radiograph did not significantly change. Pulmonary functions showed slight improvement in total lung capacity and diffusing capacity.

\section{Histologic findings}

The open-lung biopsy shows a diffuse involvement of the interstitium by mild fibrosis, without honeycombing (Fig. 4). There is a mild diffuse interstitial inflammatory infiltrate. Airspace organization is not prominent. There are no uninvolved alveolar walls.

\section{Discussion}

The most important concept to understand about this case is why it is not UIP. In the past, UIP was often used as a wastebasket diagnosis for any interstitial pneumonia for which a more specific diagnosis could not be rendered. It is now recognized that UIP shows very distinctive histologic findings and is a diagnosis that carries significant implications (namely, IPF) with the majority of patients dying within 5 years $(2,4,6)$. UIP is not a diagnosis that should be made without careful consideration of its implications.

Liebow's classification of chronic interstitial pneumonias and current designations for these lesions $(2,9)$ are shown in Table 1. 

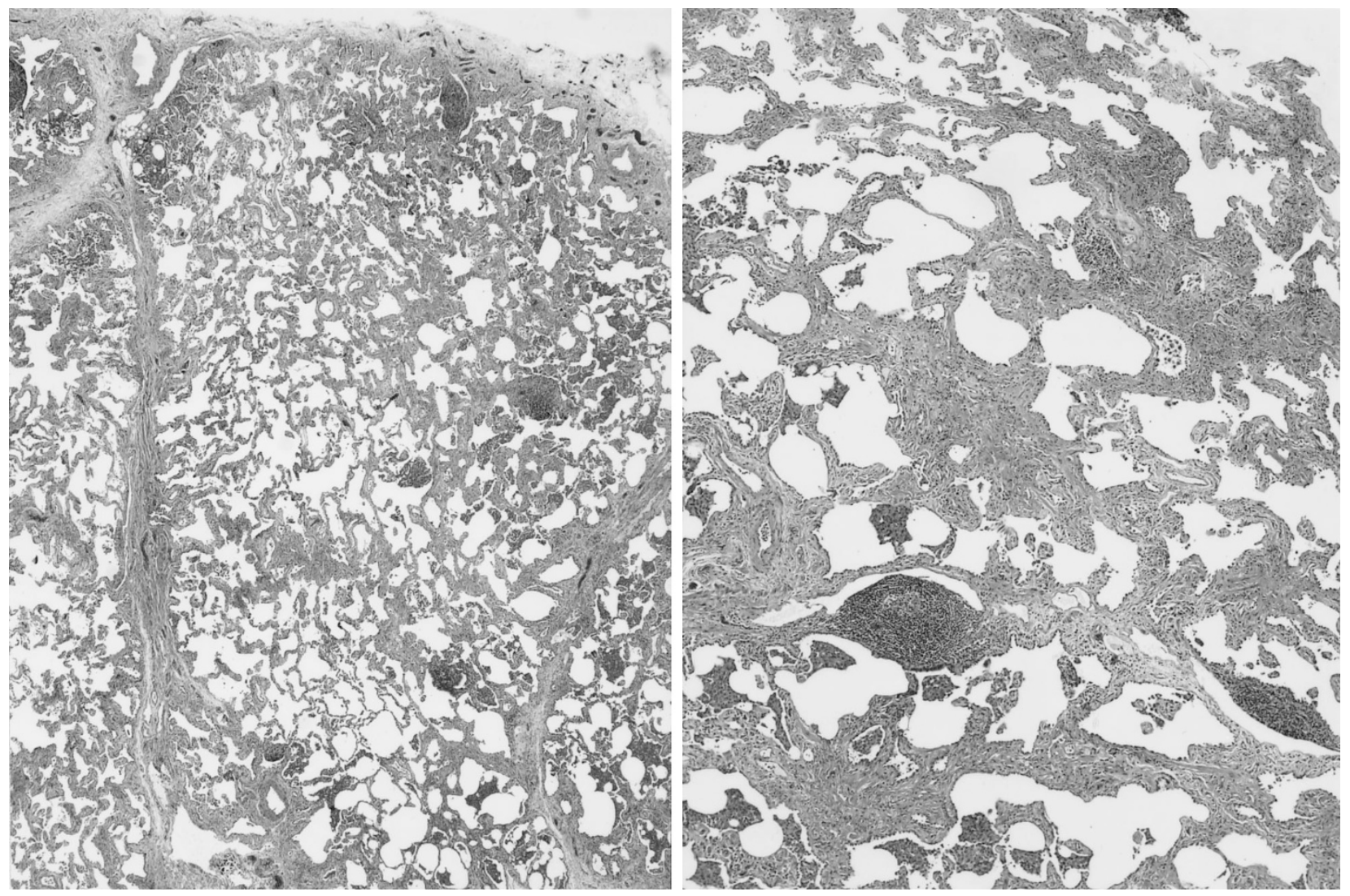

FIGURE 4. Nonspecific interstitial pneumonia. Scanning power microscopy (left) shows an absence of honeycomb change and relatively uniform involvement of the lung parenchyma by mild interstitial widening and inflammation (left). Higher power shows fibrosis of alveolar walls that appears relatively uniform in age, associated with a mild interstitial inflammatory infiltrate and occasional lymphoid follicles (right).

TABLE 1. Liebow's Classification and Current Designations of Chronic Interstitial Pneumonias

\begin{tabular}{ll}
\hline Liebow's Classification & Current Designation \\
\hline UIP & IPF \\
DIP & DIP/RBILD spectrum (see Case 2) \\
Lymphocytic & Lymphocytic interstitial pneumonia (rare; \\
interstitial & many cases considered \\
pneumonia & lymphoproliferative diseases) \\
Giant cell interstitial & Hard metal lung disease (cobalt \\
pneumonia & sensitivity) \\
Bronchiolitis obliterans & Idiopathic BOOP (cryptogenic organizing \\
with interstitial & pneumonitis/COP) \\
pneumonia & \\
\hline
\end{tabular}

UIP, usual interstitial pneumonia; IPF, idiopathic pulmonary fibrosis; DIP, desquamative interstitial pneumonia; RBILD, respiratory bronchiolitis interstitial lung disease; BOOP, bronchiolitis obliterans organizing pneumonia.

In any organ system, there are cases that are not readily classifiable. It is one of our jobs as pathologists to continually sift and sort, to develop clinicopathologic groups, and to "classify" lesions. To recognize a category of unclassifiable interstitial pneumonias, one must understand and be able to recognize those cases that are classifiable. In the context of idiopathic interstitial pneumonias, it is appropriate that strict and reproducible histologic criteria are present for lesions such as $\operatorname{UIP}(2,4,6)$. Cases of NSIP show some degree of interstitial in- filtrate, airspace organization, and interstitial fibrosis but not in the pattern of UIP or the other idiopathic interstitial pneumonias $(2,4,6,20-27)$. Extensive fibrosis and honeycomb change is not a feature of NSIP.

In published studies, cases of NSIP show variable degrees of interstitial infiltrate, airspace organization, and interstitial fibrosis, and in general, cases with more fibrosis fare worse. As a group, however, patients with NSIP do considerably better than patients with UIP $(2,6,22-27)$. An important feature in separating NSIP from UIP is that the fibrosis present shows relatively little honeycomb change, relatively more inflammatory infiltrate, and temporal uniformity rather than the characteristic temporal heterogeneity of UIP. In addition, some of the fibrous proliferation that appears interstitial on hematoxylin and eosin stains can be shown by elastic tissue stains to be airspace fibrosis, with preservation of underlying alveolar architecture (25).

Interstitial pneumonias caused by drugs and those associated with a collagen vascular disease may show all the histologic features of NSIP (22). Thus, some knowledge of the clinical history is important in characterizing and categorizing an individual case of interstitial pneumonia. 
The following lesions can now be included among the idiopathic interstitial pneumonias and related lesions. This grouping is a modification of the classification of Katzenstein and Myers (2). It should be noted that these primarily represent pathologic patterns occurring in the clinical setting of an idiopathic interstitial pneumonia.

AIP has the appearance of organizing DAD $(2,28$, 29). Some residual hyaline membranes may be identified as lining airspaces. The predominant pattern of AIP is one of diffuse, fairly uniform interstitial edema with spindled fibroblasts (without much collagen deposition), some organization within airspaces, and marked atelectasis with apposition of alveolar walls imparting a low-power appearance that suggests that no normal alveoli are present. Type 2 cells are often prominent. Acute inflammation, chronic inflammation, eosinophils, and foamy alveolar macrophages are inconspicuous features. Despite the severe changes histologically, some cases that appear to have no normal alveoli actually show complete clinical resolution with recovery of all or nearly all pulmonary function if the patient survives (29).

Some interstitial pneumonias show a bronchiolitis obliterans-organizing pneumonia (BOOP) pattern, $(4,9,14,20,25,30)$ including edematous tufts of granulation-type tissue predominantly within airspaces, usually alveolar ducts but often bronchioles (hence, the "bronchiolitis obliterans" component of the diagnosis) as well as alveoli (the "organizing pneumonia" component). There is a mild to moderate interstitial infiltrate in the regions of organization, with a modest type 2 cell proliferation. Alveolar spaces may contain foamy macrophages. Eosinophils and neutrophils are inconspicuous.

BOOP is a common reaction pattern that may be seen in a variety of settings (20):

Organizing infections

Organizing DAD

Drug reactions

Organizing toxic inhalations

Collagen vascular disease

Extrinsic allergic alveolitis

Chronic eosinophilic pneumonia

Distal to obstruction

As a part of a reaction around a variety of processes

Idiopathic (idiopathic BOOP)

UIP, acute exacerbation of IPF, DIP, and RBILD are discussed above.

DIP has been thought by some to be early or cellular UIP, but the histology, the radiology, and the follow-up do not support this $(2,20)$. A corollary to the suggestion that DIP is an earlier or cellular phase of UIP is the notion that cases of UIP have an early or cellular phase, which is not the case. Cases that appear clinically or radiographically "early" are actually cases of UIP with relatively little parenchymal destruction, but the affected parenchyma is chronically and irreversibly altered (i.e., chronic in these foci). Rather than one injurious event that has early and late phases in UIP, there are multiple tiny events scattered throughout the lung parenchyma and at any given point in time, some of these are pathologically young (fibroblastic foci), whereas others are pathologically old (i.e., honeycomb change).

\section{CASES 4 AND 5: BRONCHIOLITIS}

Pathologic abnormalities in the small airways produce a variety of clinical radiologic syndromes that vary from airflow obstruction with luminal obliteration and radiologic hyperinflation to restrictive disease with peribronchiolar cellular infiltration and fibrosis, luminal preservation, and radiologic infiltrates. All combinations and permutations of these extremes may be encountered. The following two cases illustrate this clinicopathologic spectrum. Case 5 also highlights the variety of pathologic changes in the lungs that are associated with chronic inflammatory bowel disease.

The easiest way to appreciate airway disease in a surgical lung biopsy is at scanning power microscopy. The pathologic changes show a predilection for the airways, with relative sparing of the alveoli as one nears the pleura or a septum. Some cases may be more difficult to evaluate when chronic airway disease has led to recurrent pneumonias, resulting in zones of organization and/or scarring that involve the parenchyma distal to the affected airways. In such cases, careful scanning power microscopic evaluation of all available tissue should allow one to identify the airway lesions as predominant.

\section{Case 4: Idiopathic Constrictive Bronchiolitis}

A 59-year-old woman presented with 18 months of progressive obstructive lung disease dated to a bout of the flu. Single lung transplant was performed, and the sections are from the explanted lung. She later developed necrotizing cholecystitis and died of abdominal sepsis 6 months after transplantation.

\section{Histologic findings}

The lung tissue appears remarkably normal (Fig. 5A). Nevertheless, there are subtle abnormalities involving most of the small airways. These abnormalities include mild chronic cellular bronchiolitis, nearly normal bronchioles, bronchiolectasia with mucostasis, bronchioles that are smaller than their accompanying pulmonary artery, bronchioles that 


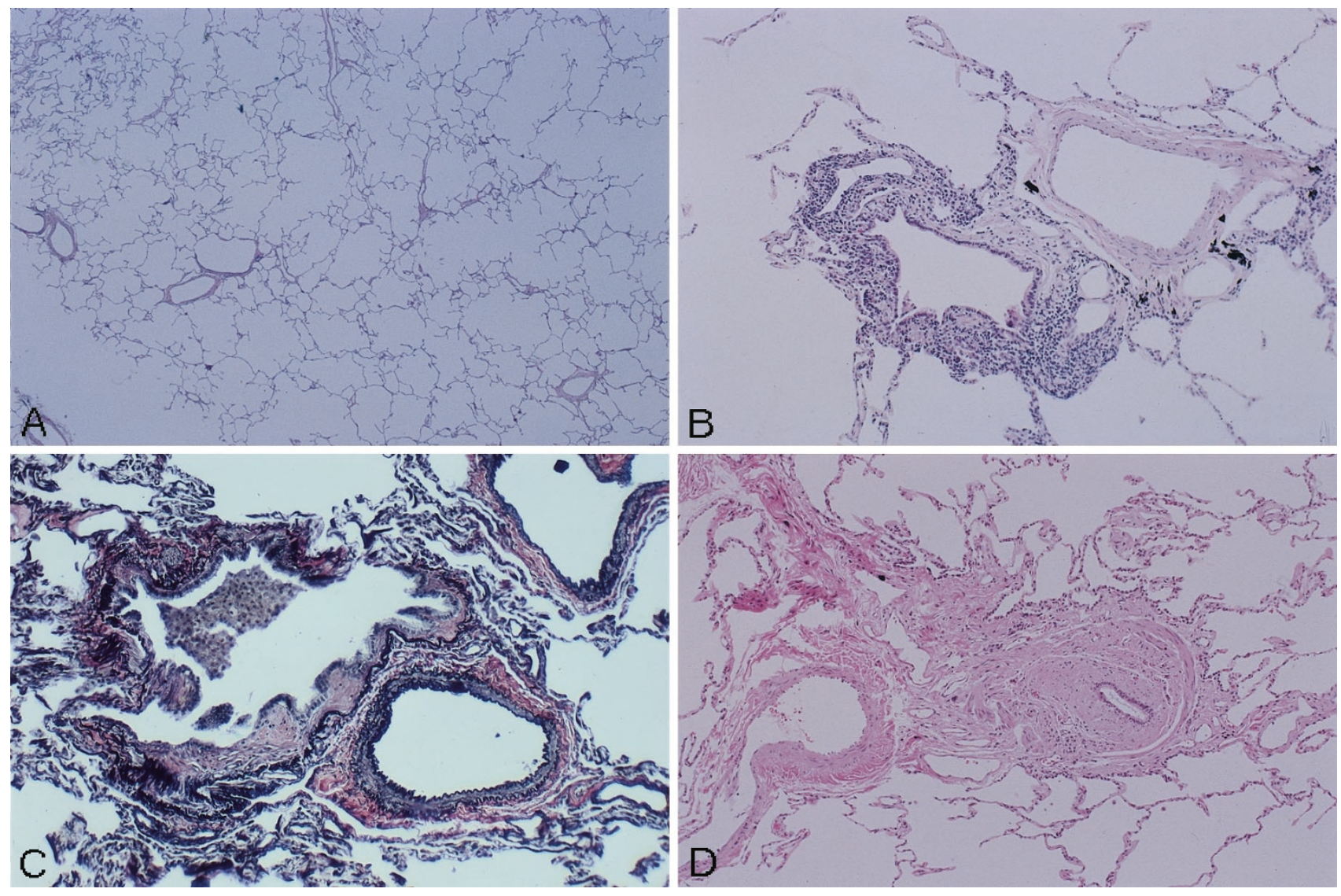

FIGURE 5. Idiopathic constrictive bronchiolitis. Scanning power microscopy is deceptively normal except for mild emphysema (A). Careful inspection of lung tissue shows abnormal bronchioles with mild chronic bronchiolitis (B) and bronchioles that appear somewhat distorted with cells in their lumina and submucosal scarring (C, elastic tissue stain). Some bronchioles show complete or near complete (D) obliteration with little associated inflammation.

show submucosal thickening and scarring, and bronchioles that are completely obliterated (Fig. 5 B-D). Examination of over 30 blocks in this case revealed that less than $10 \%$ of the small airways showed complete obliteration.

\section{Discussion}

Bronchiolar abnormalities and their terminology have been confusing for both clinicians and pathologists. The basic problem is that some cases that show pathologic findings in the small airways manifest as interstitial/restrictive lung disease, whereas others manifest as obstructive lung disease (31-40). Thus, it is important to know precisely the context in which the various terms associated with bronchiolitis are being used, in particular whether they are used in a clinical or strictly pathologic context. One can divide most surgical pathology problems of bronchiolitis into the following descriptive groups (40):

Cellular bronchiolitis (with germinal centers, "follicular bronchiolitis"). There are acute or chronic cellular infiltrates in or along bronchioles. Cellular bronchiolitis may be associated with interstitial/restrictive lung disease and/or obstructive lung disease. There may also be associated bron- chiolitis obliterans with intraluminal polyps or constrictive bronchiolitis.

Bronchiolitis obliterans with intraluminal polyps, also called "bronchiolitis obliterans." This histologic finding is usually associated with interstitial disease, clinically. Organizing pneumonia (airspace organization) is usually an accompanying finding (i.e., BOOP pattern).

Constrictive bronchiolitis, also called "bronchiolitis obliterans." Constrictive bronchiolitis is typically associated with airflow obstruction and hyperinflation radiologically. An associated cellular bronchiolitis is commonly present, as in the case discussed. Constrictive bronchiolitis rarely has concurrent bronchiolitis obliterans with intraluminal polyps and is primarily restricted to membranous bronchioles. Constrictive bronchiolitis is a useful term to separate cases showing this pattern from those showing bronchiolitis obliterans with intraluminal polyps, because the term "bronchiolitis obliterans" has often been used for both of these histologic findings (40). Causes of constrictive bronchiolitis include (20, 40-45):

Healed infections (especially viral/mycoplasma) Toxic/fume exposure or ingestion 


\section{Bronchiectasis}

COPD

Connective tissue diseases

Bone marrow or heart/lung transplantation

Inflammatory bowel disease (IBD)

Drug reactions

Bronchiolar neuroendocrine cell hyperplasia

Healed bronchopulmonary dysplasia

Idiopathic

Case 4 represents an example of idiopathic constrictive bronchiolitis. Given the history, this may be an example of postinfectious constrictive bronchiolitis if one believes that she had the flu.

The key point for the pathologist reviewing the pathology of constrictive bronchiolitis is to appreciate the subtlety of the findings $(32-34,36-39,40)$. The findings of constrictive bronchiolitis primarily involve membranous bronchioles and include varying degrees of submucosal concentric scarring, mural thickening, smooth muscle hyperplasia, bronchiolectasia, decrease in size of bronchioles compared with the accompanying pulmonary artery, cellular bronchiolitis, and complete obliteration. The last change is the most dramatic and the one that is usually illustrated, but it is actually much less common than the other changes. The accompanying pulmonary arteries often show some nonspecific mural thickening, which should not be taken as evidence of associated pulmonary hypertension.

From the practical point of view, one often has to decide whether subtle changes in the small airways are clinically significant or not. In a patient with known obstructive lung disease in whom a biopsy is performed for a diagnosis, the subtle changes are most likely to be significant. Minor abnormalities in the bronchioles are common in patients with interstitial pneumonias and patients who smoke (15). Mild pathologic changes are commonly identified in resections for carcinoma but are usually an incidental finding. Thus, it is critical to know whether the patient has been a smoker when evaluating lesions in small airways. Localized processes, such as bronchiectasis, may be associated with scarring of small airways, producing changes identical to those seen in widespread constrictive bronchiolitis, but knowledge of the clinical circumstances allows separation of local changes from a clinically significant diffuse process.

\section{Case 5: Suppurating Acute and Chronic}

Bronchiolitis Associated with Inflammatory Bowel Disease (Case courtesy of Dr. Walter Finkbeiner, University of California, San

Francisco)

\section{History}

A 16-year-old boy with a history of Crohn's disease presented with bilateral nodular pulmonary infil- trates. An open-lung biopsy was performed. Cultures and special stains were negative. The patient's pulmonary lesions resolved after steroid therapy.

\section{Histologic findings}

The biopsy specimen shows marked acute and chronic cellular bronchiolitis with acute inflammation in bronchiolar lumina and chronic inflammation in the wall (Fig. 6A and B). There are zones of suppuration and abscess formation, with large pools of neutrophils and destruction of lung tissue (Fig. 5C). The surrounding lung tissue shows fibrin
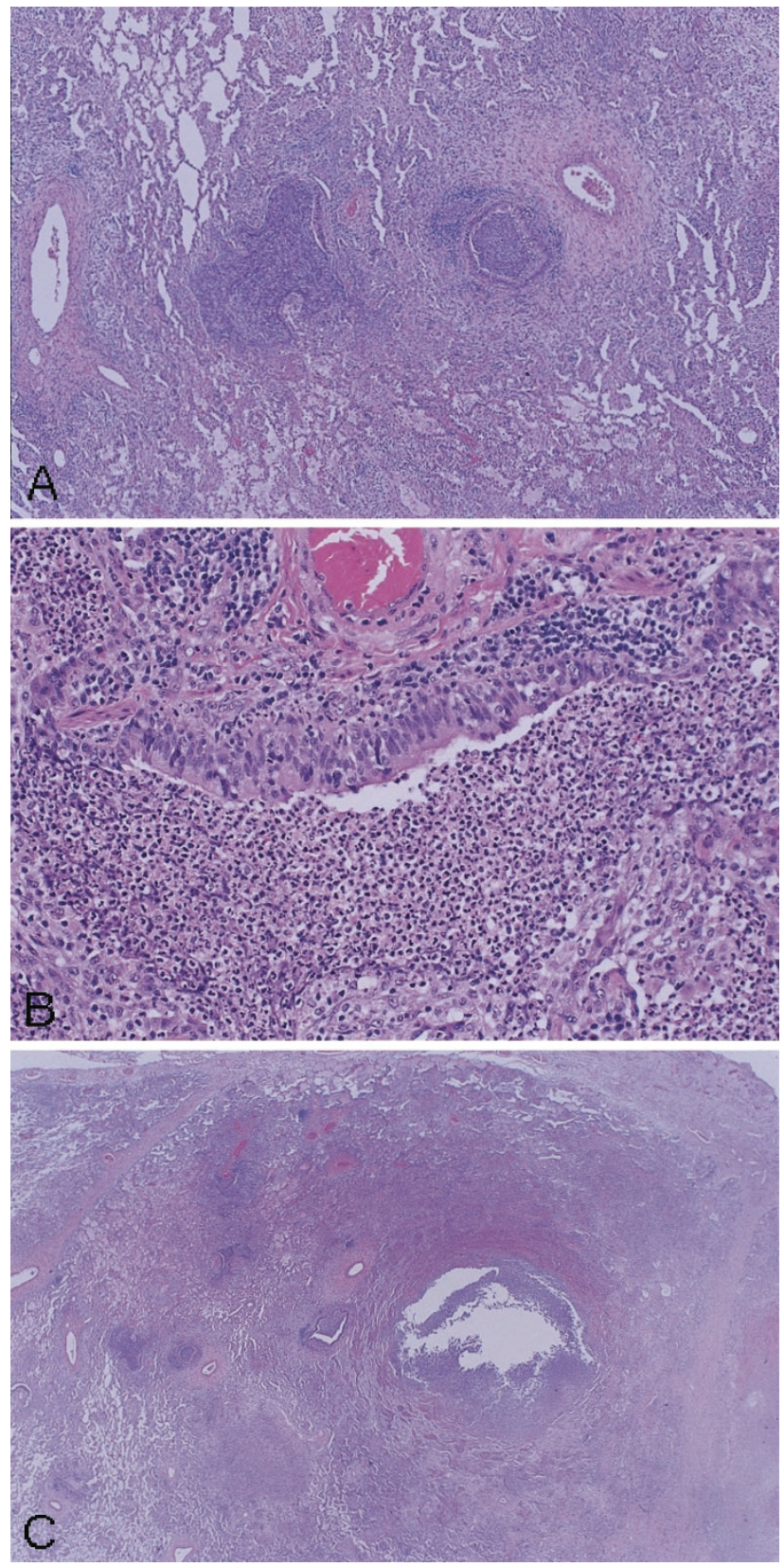

FIGURE 6. Suppurative acute and chronic bronchiolitis associated with inflammatory bowel disease. The inflammatory process shows a predilection for bronchioles (A) with neutrophils filling the lumen and chronic inflammation in the wall (B). In some regions, there is suppuration with destruction of lung architecture resembling pyoderma gangrenosum in the skin $(\mathbf{C})$. 
accumulation, organization, interstitial inflammation, and reactive type 2 cells. Giant cells and granulomatous features are lacking.

\section{Discussion}

Infection should be the first thought in a case showing this many neutrophils. In that regard, it is extremely important to know that special stains were negative and that appropriate cultures were obtained (and proved to be negative). Nevertheless, one would be reluctant to exclude an infection absolutely, and the possibility should always be kept in the back of one's mind whenever there is this degree of suppuration. The lack of granulomatous features excludes most granulomatous infections. One organism that may produce features similar to this and yet be difficult to identify by culture (and have few organisms histologically) is actinomycosis. Because there is purulent bronchiolitis adjacent to the zones of suppuration, it is likely that the basic process is a suppurating bronchiolitis.

The key in this case is the clinical history of IBD (Crohn's disease). There are a number of pleuropulmonary complications associated with IBD (4656); for the most part, they are associated with ulcerative colitis (50). The earliest reports of lung disease associated with IBD were of chronic bronchial suppuration progressing to bronchiectasis, an inflammatory disease of the large airways for which no cause could be found other than the coincident IBD $(46,47)$. For manifestations of thoracic involvement in IBD that are now recognized, see Table 2 (50).

Large airway lesions in IBD generally show a dense band-like infiltrate of lymphocytes and plasma cells underlying metaplastic bronchial mucosa (50). Germinal centers are not prominent.

The bronchiolar lesions associated with IBD include acute and chronic cellular bronchiolitis and varying degrees of bronchiolar scarring $(49,50)$. Gran-

TABLE 2. Manifestations of Thoracic Involvement in IBD (50)

\begin{tabular}{lc}
\hline & $\begin{array}{c}\text { \% of Total Cases } \\
\text { (Approx) }\end{array}$ \\
\hline Large airway & 7 \\
Subglottic stenosis & 20 \\
Chronic bronchitis & 8 \\
Chronic bronchial suppuration & 22 \\
Bronchiectasis & 4 \\
Small airway & 13 \\
Bronchiolitis & 4 \\
Interstitial lung disease & 16 \\
BOOP & \\
Pulmonary infiltrates with eosinophilia & 6 \\
Other interstitial lung diseases (most & \\
$\quad$ with no histologic confirmation) & \\
Pulmonary nodules & \\
Necrobiotic/suppurative nodules &
\end{tabular}

ulomas may be seen in Crohn's disease (56). Some cases show constrictive bronchiolitis with severe airflow obstruction. Active inflammatory lesions may eventually progress to inactive scarred lesions in the small airways. Some cases are histologically indistinguishable from diffuse panbronchiolitis (57).

The histologic patterns of interstitial lung disease include nonspecific inflammatory interstitial infiltrates, bronchiolitis obliterans with patchy organizing pneumonia, and eosinophilic infiltrates resembling eosinophilic pneumonia (50).

Necrobiotic nodules are best characterized conceptually as "pyoderma of the lung" with flooding of the airspaces by neutrophils and necrosis of lung parenchyma with surrounding fibrinous exudate and organization (50). Extensive vasculitis, giant cells, and granulomatous features are generally absent, and this helps distinguish this lesion from granulomatous infections and Wegener's granulomatosis. The case under discussion includes both acute bronchiolitis and suppurative foci. The differential diagnosis of this sort of suppurative nodule in the lung includes pulmonary involvement in pyoderma gangrenosum (58), as well as Sweet's syndrome $(59,60)$. Even though the features do not suggest vasculitis, the high frequency of positive antineutrophil cytoplasmic antibody (ANCA) tests (particularly p-ANCA) in the setting of IBD (61) could lead to a consideration of vasculitis in differential diagnosis.

Patients with IBD are usually under treatment, and a drug reaction (especially to sulfa drugs) is always in the differential diagnosis, especially in cases that show interstitial lung disease clinically (50).

\section{CASES 6 AND 7: GRANULOMATOUS LESIONS}

Granulomatous inflammation is a common problem in the surgical pathology of the lung. Most cases fall into one of the following groups: diffuse interstitial pneumonia with granulomas or multifocal/nodular/ consolidative disease with necrosis. The following two cases are illustrative of these two groups.

\section{Case 6: Wegener's Granulomatosis (WG)- The Full Histologic Spectrum}

\section{History}

A 75-year-old man presented with acute dyspnea, hemoptysis, and alveolar infiltrates a few weeks after a skin biopsy had been diagnosed as "vasculitis." An open-lung biopsy was performed. The patient began receiving steroids, with good response, but he returned with pulmonary infiltrates after he discontinued steroid therapy. Repeat chest radio- 
graphs showed patchy consolidation more prominent in the upper lobes. A second open-lung biopsy was performed. The patient began receiving steroids and cyclophosphamide and had prompt remission of signs and symptoms. On the day of discharge, he suffered a cerebrovascular accident and died. No autopsy was performed.

The first biopsy reveals alveolar hemorrhage and hemosiderin-filled macrophages with mild inflammatory changes in the alveolar walls (Fig. 7A). Capillaritis is not present. Specific features of WG are not present. The findings are simply those of alveolar hemorrhage of an unknown cause.

The second biopsy reveals extensive consolidation of lung parenchyma with associated geographic necrosis developing in the zones of consolidation (Fig. 7B). There is fibrosis and marked acute and chronic inflammatory reaction that involves airways, vessels, and lung parenchyma. Within this background, there are microabscesses of neutrophils surrounded by palisaded histiocytes and scattered giant cells (Fig. 7C). The microabscesses coalesce to form the large geographic zones of necrosis. Microabscesses within the walls of vessels (Fig. 7D) and cartilaginous destruction (chondritis) are also present. Within the adventitia of large bronchovascular bundles, small vessel vasculitis (capillaritis/ leukocytoclastic vasculitis) was present.

\section{Discussion}

This case illustrates the full histologic spectrum of WG, which varies from nondescript alveolar hemorrhage to massive consolidation with geographic necrosis and extensive vasculitis (62). The second biopsy shows the classic histologic features of WG.

The clinical triad of WG includes involvement of the upper respiratory tract, lower respiratory tract, and kidney (63); however, only a minority of cases show involvement of all three sites at presentation (62), and the isolated involvement of many sites is well described. The clinical spectrum of WG is also broad and varies from localized indolent disease to a fulminant multisystem process that rapidly leads to death with respiratory or renal failure $(62,64-$ $66)$.

Recently, serologic studies for ANCAs have proved useful in the diagnosis of vasculitis, in general, and
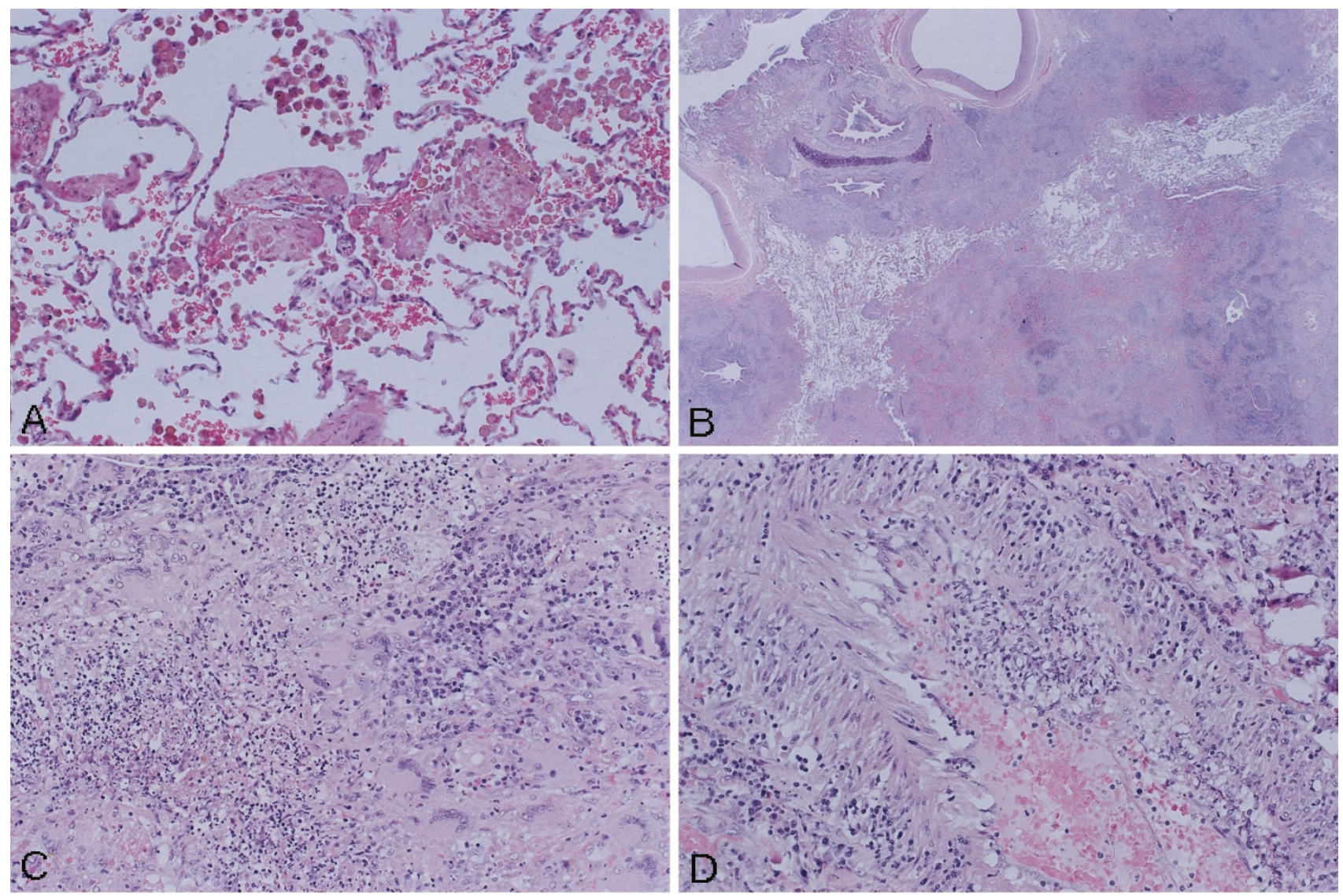

FIGURE 7. Wegener's granulomatosis. Biopsy 1 shows hemosiderin-filled macrophages, scattered red blood cells, and a few tufts of organization, typical of organizing alveolar hemorrhage (A). Biopsy 2 shows zones of consolidation with intervening normal lung tissue (B). In some regions, arteries are unaffected (B, upper center). Zones of basophilic necrosis, sometimes showing a geographic character (B, lower right) are apparent. At higher power, basophilic necrosis is seen arising from microabscesses of neutrophils surrounded by giant cells without sarcoid-like granulomas (C) Occasional medium-sized pulmonary arteries show vasculitis composed of an eccentric infiltrate of neutrophils and associated monocyte-like cells (D) 
WG, in particular $(61,62,67-70)$. Approximately $80 \%$ of patients with WG obtain positive ANCA test results, usually c-ANCA (antiProteinase 3/PR3), although a small percentage of patients obtain positive p-ANCA (antimyeloperoxidase/MPO) test results (61). c-ANCA is named for the cytoplasmic staining pattern on immunofluorescence, whereas p-ANCA is named for the perinuclear pattern of staining. Enzyme-linked immunosorbent assays are available now for both pand c-ANCA $(67,69,70)$.

ANCA results are useful to the pathologist; positive c-ANCA results are good evidence in support of WG, and negative c-ANCA results (in the presence of multisystem involvement) are evidence against the diagnosis (62). Needless to say, the findings from ANCA studies are not always definitive, and some cases of WG have negative ANCA results; in these cases the diagnosis rests solely on the pathologic findings.

c-ANCA has a higher specificity than p-ANCA, especially for WG $(61,62,69,70)$. Only rarely are false positives encountered with c-ANCA, whereas p-ANCA positivity may be seen in a variety of settings, including other vasculitic syndromes, collagen vascular disease, IBD (where the frequency is quite high), and a number of other conditions. Both p-ANCA and c-ANCA positivity may be observed in syndromes with glomerulonephritis, not all of which are associated with pulmonary disease. Prospective studies have suggested that using ANCA tests alone as screening tools is not appropriate unless taken in context (71).

A minority of cases of WG show only alveolar hemorrhage (62). As such, they are similar to other cases of alveolar hemorrhage $(62,72)$ and include the following changes histologically: fresh and old hemorrhage and airspaces, patchy airspace organization, and mild interstitial reaction in type 2 cell hyperplasia. Capillaritis (73) may or may not be present. When microabscesses and scattered giant cells are identified, they are good evidence in support of WG, and the appearance merges with that described below.

The most common pattern of WG in the lung is parenchymal consolidation/nodule formation. The pathologic findings include three basic components: vasculitis, parenchymal necrosis, and inflammatory background, and the proportion of these varies from case to case.

There have been several studies addressing the surgical pathology of WG in the lung (74-76). These studies have attempted to identify discriminating features in the differential diagnosis, which can be summarized as follows:

Vasculitis involving arteries, veins, and capillaries (capillaritis/leukocytoclastic capillaritis); palisaded granulomas/microabscesses within vessel walls that may assume a crescent shape, with partial involvement of the wall.

Necrosis as microabscesses that coalesce to large geographic basophilic zones of necrosis.

Granulomatous inflammation, including palisaded histiocytic reaction around microabscesses and basophilic necrosis, scattered giant cells among zones, and consolidation; granulomatous bronchiolitis.

Note: Sarcoid-like granulomas are rare or lacking.

Additional features: acute inflammation, chronic inflammation, fibrinous exudate, airspace organization (BOOP pattern) (77), interstitial fibrosis, acute or old alveolar hemorrhage, xanthomatous reactions, lymphoid aggregates, necrotizing chondritis, eosinophilic infiltration (78), bronchocentric necrosis (79), et al.

The above features may be altered by treatment (80), and some cases may show bland fibrosis with mild inflammation and scattered giant cells without necrosis or active vasculitis.

No one histologic feature can be used to make the diagnosis of WG. Each case must be individualized, and clinical data, serologic data, and biopsies of other sites (e.g., nose) may be extremely helpful. The pathologic findings are part of a database on which the diagnosis rests, and there are cases that may not necessarily show all the histologic changes that one would like to find yet they are still sufficient to support a strong clinical and serologic impression of Wegener's granulomatosis.

The differential diagnosis of WG can be divided into these five groups (62):

Nonspecific/miscellaneous inflammatory reactions

Alveolar hemorrhage syndromes

Granulomatous infections and other necrotic nodules (e.g., rheumatoid nodules)

Other vasculitic syndromes

Other forms of angiitis and granulomatosis

At its most basic level, WG is an inflammatory process, and unless the distinctive vasculitis and granulomatous necrosis are present, the only findings may be nonspecific inflammation. Lack of characteristic features should not lead one to definitively exclude the possibility of WG.

WG may be associated with alveolar hemorrhage that is indistinguishable from other causes of diffuse alveolar hemorrhage, such as collagen vascular diseases, other vasculitis syndromes, antiglomerular basement membrane antibody disease (Goodpasture's disease), and others (72).

Compared with granulomatous infections (62), WG tends to have geographic necrosis rather than rounded zones of necrosis and more extensive con- 
solidation and inflammatory destruction of lung tissue relative to the amount of necrosis. Capillaritis is characteristic of WG and is rarely seen in granulomatous infections. Granulomatous infections typically have non-necrotizing sarcoid-like granulomas away from the zones of necrosis and rarely show the scattered, somewhat hyperchromatic giant cells that are so characteristic of WG. Rheumatoid nodules typically occur in the setting of rheumatoid arthritis and are similar to rheumatoid nodules at other sites.

The separation of WG from other vasculitic syndromes is usually based on the constellation of clinical findings and serologic data (62). The duty of the pathologist is to identify the pathologic findings present and indicate whether the characteristic features of WG (granulomatous necrosis and giant cells) are present or absent.

WG is occasionally confused with other forms of the so-called angiitis and granulomatosis (62). Churg-Strauss syndrome (allergic granulomatosis) is a separate and distinct vasculitic syndrome occurring in asthmatics. Lymphomatoid granulomatosis is a lymphoproliferative process and lacks the granulomatous necrosis and scattered giant cells present in WG. WG may have bronchocentric necrotizing lesions, hence resembling bronchocentric granulomatosis, and the latter condition is usually found in patients with asthma and allergic bronchopulmonary aspergillosis or other granulomatous infections. Necrotizing sarcoid granulomatosis is confluent granulomatous nodules of sarcoidosis ("nodular sarcoid") showing necrosis. There are numerous non-necrotizing (sarcoid-like) granulomas.

\section{Case 7: Mycobacterium Avium Intracellulare- Associated Diffuse Lung Disease in a Nonimmunosuppressed Patient}

\section{History}

A 36-year-old man presented with multiple, bilateral, small (miliary) pulmonary nodules. He was receiving dialysis for chronic renal failure caused by renovascular hypertension. He was not receiving immunosuppressive therapy.

\section{Histologic findings}

The open-lung biopsy shows scattered, individual non-necrotizing granulomas (Fig. 8A). These are associated with a cuff of lymphocytes (Fig. 8B). Some granulomas were bronchiolocentric; some were randomly scattered in the parenchyma. The pleura was uninvolved. Coalescence of granulomas was not prominent. Multiple special stains for acidfast organisms and fungal organisms were negative. Culture results were positive for Mycobacterium avium intracellulare (MAI).
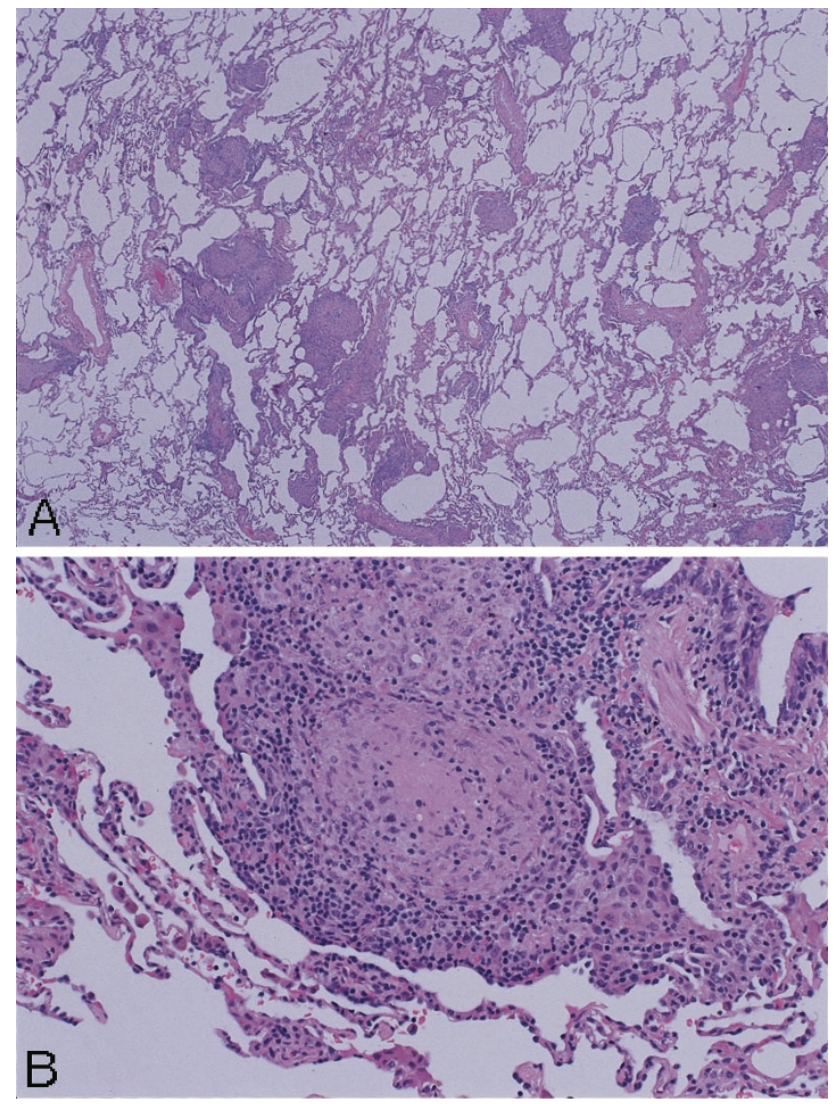

FIGURE 8. Mycobacterium avium intracellulare-associated diffuse lung disease in a normal host. Low power microscopy shows scattered solitary granulomas with a cuff of lymphocytes $(\mathbf{A})$. There is no predilection for coalescence of the granulomas, and they do not appear to show a specific distribution. Higher power microscopy shows sarcoid-like granulomas with a relatively prominent cuff of lymphocytes (B).

\section{Discussion}

MAI infection has become widely known as an opportunistic infection in the population with acquired immunodeficiency syndrome. However, as one of the atypical mycobacteria, it has been recognized for many years, occasionally causing cavitary disease that mimics Mycobacterium tuberculosis, as well as a number of other manifestations (81-95). Patients with chronic airway disease, particularly bronchiectasis, may be colonized by MAI, and in a small proportion, a low-grade infection develops, which may manifest as radiologic nodules associated with bronchiectasis $(89,90)$. MAI has rarely been associated with eosinophilic pneumonia (96).

The case presented illustrates a pattern of MAI infection that is increasingly recognized, that of diffuse lung disease (either micronodular or ground glass) in a normal host, without airway disease (87, 90-92, 95). Some of these cases have been associated with hot tub exposures, and in one report, several cases were identified from the use of one hot tub (91). The authors of that study concluded that it was difficult to determine whether the pul- 
monary disease represented hypersensitivity pneumonitis because of MAI or an MAI infection. The authors favored hypersensitivity, but in my (unpublished) experience with approximately 15-20 cases of MAI that causes diffuse lung disease, the histologic features do not fit well with hypersensitivity pneumonitis, and most of the cases responded to antituberculous therapy.

Summarizing the literature (81-95), the following clinicopathologic patterns may be encountered with MAI in the lung:

Fibrocaseous disease similar to tuberculosis

Disseminated infection in the immunosuppressed population (especially with acquired immunodeficiency syndrome) with nodular histiocytic proliferations containing numerous organisms

Localized/patchy nodular disease complicating chronic airway disease, especially bronchiectasis

Diffuse interstitial/nodular disease in normal hosts (as in the case presented)

Eosinophilic pneumonia

MAI-associated diffuse lung disease in normal hosts should primarily be distinguished from sarcoidosis and extrinsic allergic alveolitis. In sarcoidosis, non-necrotizing granulomas coalesce and are found along lymphatic routes (in the pleura and septa and along bronchovascular bundles) (20). The granulomas in sarcoidosis are "naked" and generally lack the cuff of lymphocytes present in MAI infection. Sarcoidosis commonly has a layer of lamellar brightly eosinophilic fibrosis around the granulomas. In extrinsic allergic alveolitis, the granulomas are overshadowed by the interstitial inflammatory infiltrate. The granulomas are small, appear "loose," are scattered throughout the parenchyma, and are sometimes composed only of loose clusters of giant cells or a few epithelioid histiocytes.

MAI-associated diffuse lung disease manifests as scattered, generally noncoalescing granulomas that may show some bronchiolocentricity (perhaps due to inhalation infection) or are randomly distributed in the lung parenchyma and not along lymphatic routes, as is the case in sarcoidosis. The granulomas typically have a cuff of lymphocytes, and the intervening lung parenchyma is relatively normal in contrast to hypersensitivity pneumonitis. Some cases also have airspace organization similar to that seen in BOOP associated with the granulomas.

\section{Case 8: Middle Lobe Syndrome (Right Middle Lobe Syndrome)}

Middle lobe syndrome is included in this discussion because of the high frequency with which the diagnosis is missed by pathologists. The critical feature in recognizing this entity is knowing the site of the biopsy and whether the patient has disease localized to the middle lobe and/or the lingula.

\section{History}

A 39-year-old man with a history of asthma presented with recurrent pneumonias in the right middle lobe. A right middle lobectomy was performed and was curative.

\section{Histologic findings}

Sections show peribronchiolar fibrosis and some bronchiolectasia (Fig. 9A). There is focal interstitial fibrosis and hemosiderin-filled macrophages in the airspaces (Fig. 9B). There is slight pleural fibrosis. Other sections showed foci of airspace organization (organizing pneumonia), active pleuritis, and focal honeycombing.

\section{Discussion}

Middle lobe syndrome (97-103) is well known to thoracic surgeons and pulmonologists but not so well known to pathologists. Unless one is aware of the entity, the constellation of histologic findings that may be observed with middle lobe syndrome may lead to an embarrassing variety of erroneous diagnoses.
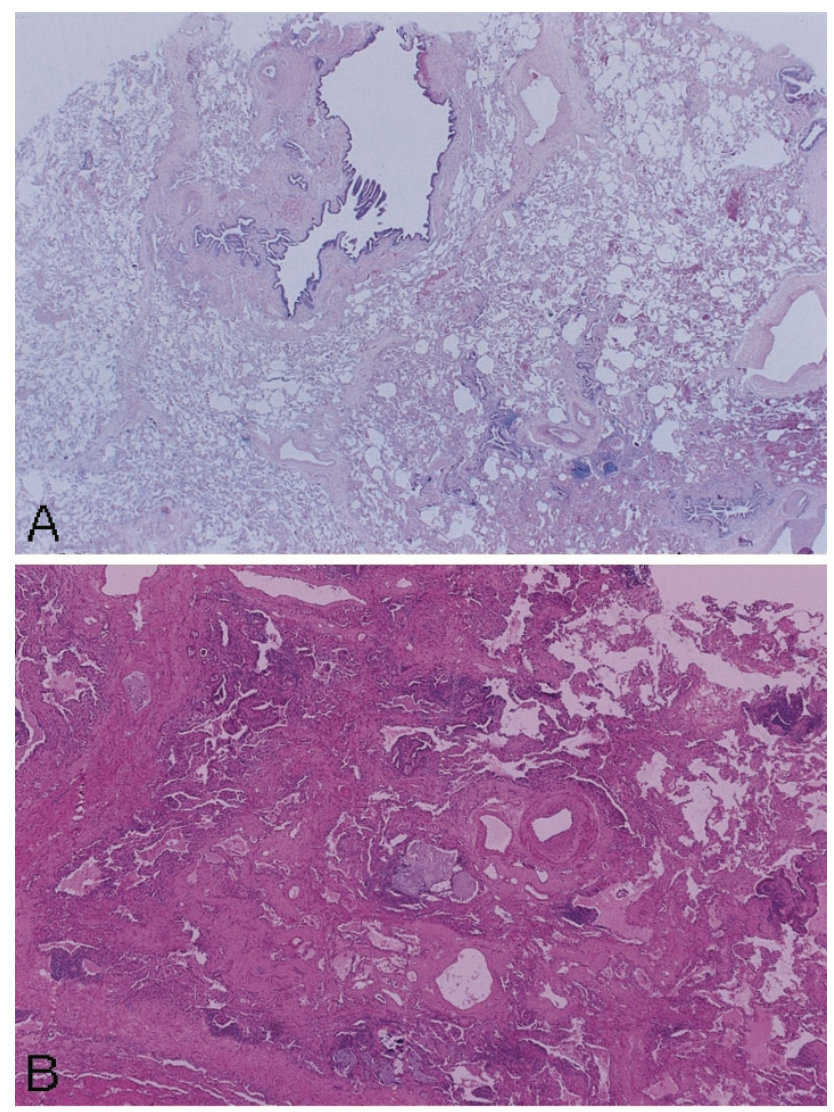

FIGURE 9. Middle lobe syndrome. In some regions, ectasia of airways is apparent with surrounding patchy scarring of the lung parenchyma (A). Other sections in this case showed extensive interstitial fibrosis, reminiscent of a fibrosing interstitial pneumonia (B). 
Middle lobe syndrome is preferable to right middle lobe syndrome, because this condition may affect the right middle lobe and/or the lingula. In early reports, the recurrent atelectasis and pneumonias found in middle lobe syndrome were thought to be the result of extrinsic compression; later, cases associated with intrinsic obstruction were also reported, as well as cases in which no apparent obstructive lesion could be shown (97$100,103)$. It has been concluded that the lingula and the right middle lobe, because of their anatomic configuration, are prone to recurrent atelectasis and as such, are prone to recurrent pneumonias that ultimately lead to bronchiectasis and a vicious cycle of inflammation, infection, and other pathologic changes (103). Some of the nonneoplastic conditions that have been associated with right middle lobe syndrome in the literature include (103)

Extrinsic bronchial obstruction: lymphadenopathy/calcification, granulomatous infection (tuberculosis, histoplasmosis), occupational dust exposure (asbestosis, anthrasilicosis), reactive lymphoid hyperplasia, esophageal traction diverticula

Intrinsic bronchial obstruction: foreign body aspiration, edema of bronchial mucosa, submucosal scarring and fibrosis, granulation tissue, mucus plug/mucoid impaction of bronchi, broncholith, endobronchial sarcoidosis

Nonobstructing associated conditions: bronchiectasis, nonspecific chronic inflammation, infarct, bronchopulmonary cyst, asthma

In the patient presented, bronchial asthma was probably the predisposing factor to recurrent atelectasis and, ultimately, to secondary infection (102).

Middle lobe syndrome is more common in women than in men (2:1) (104). Most patients present in the fifth decade of life. Symptoms include cough, hemoptysis, chest pain, dyspnea, fever, and recurrent pneumonias. Chest radiographs show bronchiectasis and/or infiltrate. Resection is the treatment of choice and is curative.

The pathologic findings in middle lobe syndrome are many and varied (103) and include bronchiectasis, acute and chronic bronchitis, acute and chronic bronchiolitis with or without lymphoid hyperplasia, airspace organization (organizing pneumonia) atelectasis, abscess formation, recent or old hemorrhage, interstitial fibrosis, honeycombing, pleuritis, and pleural fibrosis.

Bronchiectatic lung tissue (regardless of cause) is prone to secondary colonization by atypical mycobacteria (especially MAI) and the development of a low-grade infection, which correlates with the finding of nodular infiltrates on computed tomographic scans and granulomatous inflammation histologically $(88,89,103)$.

\section{REFERENCES}

1. Liebow AA, Carrington CB. Alveolar diseases. In: Simon M, editor. The interstitial pneumonias. New York: Grune \& Stratton; 1967. p. 102-41.

2. Katzenstein ALA, Myers JL. C classification. Am J Respir Crit Care Med 1998;157:1303-15.

3. Crystal RG. Idiopathic pulmonary fibrosis: clinical, histologic, radiographic, scintigraphic, cytologic and biochemical aspects. Ann Intern Med 1976;85:769-88.

4. Ryu JH, Colby TV, Hartman TE. Idiopathic pulmonary fibrosis: current concepts. Mayo Clin Proc 1998;73:1085-101.

5. Carrington CB, Gaensler EA, Coutu RE, Fitzgerald MX, Gupter RG. Natural history and treated course of usual and desquamative interstitial pneumonia. N Engl J Med 1978; 298:801-9.

6. Bjoraker JA, Ryu JH, Edwin MK, Myers JL, Tazelaar HD, Schroeder DR, et al. Prognostic significance of histopathologic subsets in idiopathic pulmonary fibrosis. Am J Respir Crit Care Med 1998;157:199-203.

7. King TE. Idiopathic pulmonary fibrosis. In: Schwarz MI, King TE, editors. Interstitial lung disease. Hamilton: BC Decker; 1998. p. 635.

8. Kondo A, Saiki S. Acute exacerbation in idiopathic interstitial pneumonia. In: Harasaka M, Fukuchi Y, Morinari H, editors. Interstitial pneumonia of unknown etiology. Tokyo: University of Tokyo Press; 1989. p. 33-42.

9. Kitaichi M. Pathologic features and the classification of interstitial pneumonia of unknown etiology. Bull Chest Dis Res Inst 1990;23:1-18.

10. Panos RJ, Mortenson R, Niccoli SA, King TE Jr. Clinical deterioration in patients with idiopathic pulmonary fibrosis. Causes and assessment. Am J Med 1990;88:396-404.

11. Kondoh Y, Taniguchi H, Kawabata Y, Yokoi T, Suzuki K, Takagi K. Acute exacerbation in idiopathic pulmonary fibrosis. Chest 1993;103:1808-12.

12. Yokoi T, Kondoh Y, Taniguchi H, Takagi K, Ono K, Kakudo K. Acute exacerbation of idiopathic pulmonary fibrosis: pathological features of 6 open biopsy cases [abstract]. Lab Invest 1997;76:174A.

13. Kuhn C, Boldt J, King TE, Crouch E, Vartio T, McDonald JA. An immunohistochemical study of architectural remodeling and connective tissue synthesis in pulmonary fibrosis. Am Rev Respir Dis 1989;140:1693-703.

14. Katzenstein AL. Acute lung injury patterns. In: Katzenstein AL, editor. Katzenstein and Askin's surgical pathology of non-neoplastic lung disease. Philadelphia: WB Saunders; 1997. p. 14-47.

15. Niewoehner DE, Kleinerman J, Rice DB. Pathologic changes in the peripheral airways of young cigarette smokers. N Engl J Med 1974;291:755-8.

16. Myers JL, Veal CF Jr, Shin MS, Katzenstein AL. Respiratory bronchiolitis causing interstitial lung disease: a clinicopathologic study of six cases. Am Rev Respir Dis 1987;135: $880-4$.

17. Bogin RM, Niccoli SA, Waldron JE, Chernick RM, Thurlbeck WM, Flint A, et al. Respiratory bronchiolitis: clinical presentation and bronchoalveolar lavage findings. Chest 1988; 94:21S.

18. Yousem SA, Colby TV, Gaensler EA. Respiratory bronchiolitis associated interstitial lung disease and its relationship to desquamative interstitial pneumonia. Mayo Clin Proc 1989; 64:1373-80.

19. Baumgartner KB, Samet JM, Stidley CA, Colby TV, Waldron JA. Cigarette smoking: a risk factor for idiopathic pulmonary fibrosis. Am J Respir Crit Care Med 1997;155:242-8. 
20. Colby TV, Swensen SJ. Anatomic distribution and histopathologic patterns in diffuse lung disease: correlation with HRCT. J Thorac Imaging 1996;11:1-26.

21. Katzenstein A. Idiopathic interstitial pneumonia: classification and diagnosis. In: Current topics in lung pathology. IAP monographic series. Baltimore: Williams \& Wilkins; 1993. p. 1-31.

22. Katzenstein A, Fiorelli RF. Nonspecific interstitial pneumonia/fibrosis: histologic features and clinical significance. Am J Surg Pathol 1994;18:136-47.

23. Cottin V, Donsbeck AV, Revel D, Loire R, Cordier JF. Nonspecific interstitial pneumonia. Individualization of a clinicopathologic entity in a series of 12 patients. Am J Respir Crit Care Med 1998;158:1286-93.

24. Myers JL. NSIP, UIP, and the ABCs of idiopathic interstitial pneumonias. Eur Respir J 1998;12:1003-4.

25. Nagai S, Kitaichi M, Ito H, Nishamura K, Izumi T, Colby TV. Idiopathic nonspecific interstitial pneumonia/fibrosis: comparison with idiopathic pulmonary fibrosis and BOOP. Eur Respir J 1998;12:1010-9.

26. Midthun DE, Ryu JH, Myers JL, Tazelaar HD, Hartman TE, Douglas WW. Nonspecific interstitial pneumonia: clinical, radiographic, and pathologic features. Am J Respir Crit Care Med 1999;157:A277.

27. Travis WD, Matsui K, Moss J, Ferrans VJ. Nonspecific interstitial pneumonia: a spectrum of cellular and fibrotic interstitial pneumonia. Am J Respir Crit Care Med 1999;159:A65.

28. Katzenstein A, Myers JL, Mazur M. Acute interstitial pneumonia: a clinicopathologic, ultrastructural, and cell kinetic study. Am J Surg Pathol 1986;10:256-67.

29. Olson J, Colby TV, Elliott CG. Hamman-Rich syndrome revisited. Mayo Clin Proc 1990;65:1538-48.

30. Epler G, Colby TV, McCloud TC, Carrington CB, Gaensler EA. Bronchiolitis obliterans organizing pneumonia. N Engl J Med 1985;312:152-8.

31. Macklem P, Thurlbeck W, Fraser R. Chronic obstructive disease of small airways. Ann Intern Med 1971;74:167-77.

32. Gosink B, Friedman P, Liebow A. Bronchiolitis obliterans. Roentgenologic-pathologic correlation. Am J Roentgenol Radium Ther Nucl Med 1973;117:816-32.

33. Geddes D, Corrin B, Brewerton D, Davies RJ, Turner-Warwick M. Progressive airway obliteration in adults and its association with rheumatoid disease. Q J Med 1997;46:427-44.

34. Turton C, Williams G, Green M. Cryptogenic obliterative bronchiolitis in adults. Thorax 1981;36:805-10.

35. Kindt G, Weiland J, Davis W, Gadek JE, Dorinsky PM. Bronchiolitis in adults. A reversible cause of airway obstruction associated with airway neutrophils and neutrophil products. Am Rev Respir Dis 1989;140:483-92.

36. Colby T, Myers J. Clinical and histologic spectrum of bronchiolitis obliterans, including bronchiolitis obliterans organizing pneumonia. Semin Respir Med 1992;13:119-32.

37. Wright J, Cagle P, Churg A, Colby TV, Myers J. Diseases of the small airways. Am Rev Respir Dis 1992;146:240-62.

38. Myers JL, Colby TV. Pathologic manifestations of bronchiolitis, constrictive bronchiolitis, cryptogenic organizing pneumonia, and diffuse panbronchiolitis. Clin Chest Med 1993;14:611-24.

39. Kraft M, Mortenson RL, Colby TV, Newman L, Waldron JA, King TE Jr. Cryptogenic constrictive bronchiolitis. Am Rev Respir Dis 1993;148:1093-101.

40. Colby TV. Bronchiolitis: pathologic considerations. Am J Clin Pathol 1998;109:101-9.

41. Aguayo SM, Miller YE, Waldron JA, et al. Idiopathic diffuse hyperplasia of pulmonary neuroendocrine cells and airway disease. N Engl J Med 1992;327:1285-8.

42. Miller R, Muller NL. Neuroendocrine cell hyperplasia and obliterative bronchiolitis in patients with peripheral carcinoid tumors. Am J Surg Pathol 1995;19:653-8.
43. Sheerin N, Harrison NK, Sheppard MN, Hansell DM, Yacoub M, Clark TJ. Obliterative bronchiolitis caused by multiple tumourlets and microcarcinoids successfully treated by single lung transplantation. Thorax 1995;50:207-9.

44. Lai RS, Chiang AA, Wu MT, Wang JS, Lai NS, Lu JY, et al. Outbreak of bronchiolitis obliterans associated with consumption of Sauropus androgynus in Taiwan. Lancet 1996; 348:83-5.

45. Chang H, Wang JS, Tseng HH, Lai RS, Su JM. Histopathological study of Sauropus androgynus-associated constrictive bronchiolitis obliterans. A new cause of constrictive bronchiolitis obliterans. Am J Surg Pathol 1997;2:35-42.

46. Kraft SC, Earle RH, Roesler M, Esterly JR. Unexplained bronchopulmonary disease with inflammatory bowel disease. Arch Intern Med 1976;136:454-9.

47. Butland RJ, Cole P, Citron KM, Turner-Warwick M. Chronic bronchial suppuration and inflammatory bowel disease. Q J Med 1981;50:63-75.

48. Gibb WRG, Dhillon DP, Zilkha KJ, Cole PJ. Bronchiectasis with ulcerative colitis and myelopathy. Thorax 1987;42:155-6.

49. Wilcox P, Miller R, Miller G, Heath J, Nelems B, Muller N, et al. Airway involvement in ulcerative colitis. Chest 1987;92: $18-22$.

50. Camus P, Piard F, Ashcroft T, Gal AA, Colby TV. The lung in inflammatory bowel disease. Medicine 1993;72:151-80.

51. Garg K, Lynch DA, Newell JD. Inflammatory airways disease in ulcerative colitis: CT and high-resolution CT features. J Thorac Imaging 1993;8:159-63.

52. Hotermans G, Benard A, Guenanen H, Demarcq-Delerue G, Malart T, et al. Nongranulomatous interstitial lung disease in Crohn's disease. Eur Respir J 1996;9:380-2.

53. Eaton TE, Lambie N, Wells AU. Bronchiectasis following colectomy for Crohn's disease. Thorax 1998;53:529-31.

54. Mahadeva R, Flower C, Shneerson J. Bronchiectasis in association with coeliac disease. Thorax 1998;53:527-9.

55. Spira A, Grossman R, Balter M. Large airway disease associated with inflammatory bowel disease. Chest 1998;113: 1723-6.

56. Vandenplas O, Casel S, Delos M, Trigaux JP, Melange M, Marchand E. Granulomatous bronchiolitis associated with Crohn's disease. Am J Respir Crit Care Med 1998;158:1676-9.

57. Desai SJ, Gephardt GN, Stoller JK. Diffuse panbronchiolitis preceding ulcerative colitis. Chest 1989;45:1342-4.

58. Vognon-Pennamen MD, Zelinsky-Gurung A, Janssen F, Frija J, Wallach D. Pyoderma gangrenosum with pulmonary involvement. Arch Dermatol 1989;125:1239-42.

59. Lazarus AA, McMillan M, Miramadi A. Pulmonary involvement in Sweet's syndrome (acute febrile neutrophilic dermatosis): preleukemic and leukemic phases of acute myelogenous leukemia. Chest 1986;90:922-4.

60. Takimoto $\mathrm{CH}$, Warnock M, Golden JA. Sweet's syndrome with lung involvement. Am Rev Respir Dis 1991;143:177-9.

61. Jennette JC, Falk RJ. Antineutrophil cytoplasmic autoantibodies in inflammatory bowel disease. Am J Clin Pathol 1993;101:221-2.

62. Colby TV, Specks U. Wegener's granulomatosis in the 1990s: a pulmonary pathologist's perspective. In: Churg A, Katzenstein AL, editors. The lung: current concepts. Baltimore: Williams \& Wilkins; 1993. p. 195-218.

63. Godman GC, Churg J. Wegener's granulomatosis: pathology and review of the literature. AMA Arch Pathol 1954;58: 533-53.

64. Brandwein S, Esdaile J, Danoff D, Tannenbaum H. Wegener's granulomatosis: clinical features and outcome in 13 patients. Arch Intern Med 1983;143:476-9.

65. Leavitt RY, Fauci AS, Bloch DA, Michel BA, Hunder GG, Arend WP, et al. The American College of Rheumatology 1990 criteria for the classification of Wegener's granulomatosis. Arthritis Rheum 1990;33:1101-7. 
66. Hoffman GS, Kerr GS, Leavitt RY, Hallahan CW, Lebovics RS, Travis WD, et al. Wegener granulomatosis: an analysis of 158 patients. Ann Intern Med 1992;116:488-98.

67. Gross WL, Schmitt SH, Csernok E. Antineutrophil cytoplasmic autoantibody-associated diseases: a rheumatologic perspective. Am J Kidney Dis 1991;18:175-9.

68. Fienberg R, Mark EJ, Goodman M, McCluskey RT, Niles JL. Correlation of antineutrophil cytoplasmic antibodies with the extra-renal histopathology of Wegener's (pathergic) granulomatosis and related forms of vasculitis. Hum Pathol 1993;24:160-8.

69. Specks U, Homburger HA. Anti-neutrophil cytoplasmic antibodies. Mayo Clin Proc 1994;69:1197-8.

70. Gross WL, Csernok E. Immunodiagnostic and pathophysiologic aspects of antineutrophil cytoplasmic antibodies in vasculitis. Curr Opin Rheumatol 1995;7:11-9.

71. Edgar JD, McMillan SA, Bruce IN, Conlan SK. An audit of ANCA in routine clinical practice. Postgrad Med J 1995;71: 605-12.

72. Travis WD, Colby TV, Lombard C, Carpenter HA. A clinicopathologic study of 34 cases of diffuse pulmonary hemorrhage with lung biopsy confirmation. Am J Surg Pathol 1990;14:1112-25.

73. Mark EJ, Ramirez JF. Pulmonary capillaritis and hemorrhage in patients with systemic vasculitis. Arch Pathol Lab Med 1985;109:413-8.

74. Mark EJ, Matsubara O, Tan-liu NS, Fienberg R. The pulmonary biopsy in the early diagnosis of Wegener's (pathergic) granulomatosis: a study based on 35 open lung biopsies. Hum Pathol 1988;19:1065-71.

75. Travis WD, Hoffman SG, Leavitt RY, Pass HI, Fauci AS. Surgical pathology of the lung in Wegener's granulomatosis. Am J Surg Pathol 1991;15:315-33.

76. Galateau F, Loire R, Capron F, Delajartre AY, Brambilla E, Bejui-Thivolet F, et al. Pulmonary lesions in Wegener's disease. Report of the French anatomo-clinical research group. Study of 40 pulmonary biopsies [English abstract]. Rev Mal Respir 1992;9:431-42.

77. Uner AH, Rozum-Slota B, Katzenstein AL. Bronchiolitis organizing pneumonia (BOOP)-like variant of Wegener's granulomatosis. A clinicopathologic study of 16 cases. Am J Surg Pathol 1996;20:794-801.

78. Yousem SA, Lombard CM. The eosinophilic variant of Wegener's granulomatosis. Hum Pathol 1988;19:682-8.

79. Yousem SA. Bronchocentric injury in Wegener's granulomatosis: a report of five cases. Hum Pathol 1991;22:535-40.

80. Mark EJ, Flieder DB, Matsubara O: Treated Wegener's granulomatosis: distinctive pathological findings in the lungs of 20 patients and what they tell us about the natural history of the disease. Hum Pathol 1997;28:450-8.

81. Rosenzweig DY. Pulmonary mycobacterial infections due to Mycobacterium intracellular avium complex: clinical features and course in 100 consecutive cases. Chest 1979; 75:115-9.

82. Wolinsky E. Nontuberculous mycobacteria and associated diseases. Am Rev Respir Dis 1979;119:107-25.

83. Marchevsky A, Damsker B, Gribetz A, Tepper S, Geller SA. The spectrum of pathology of nontuberculous mycobacterial infections in open lung biopsy specimens. Am J Clin Pathol 1982;78:695-700.

84. Farhi DC, Mason UG III, Horsburgh CR Jr. Pathologic findings in disseminated Mycobacterium avium intracellulare infection. A report of 11 cases. Am J Clin Pathol 1986;85:67-72.

85. Contreras MA, Cheung OT, Sanders DE, Goldstein RS. Pul- monary infection with nontuberculous mycobacteria. Am Rev Respir Dis 1988;137:149-52.

86. du Moulin GC, Stottmeier KD, Pelletier PA, Tsang AY, Hedley-Whyte J. Concentration of Mycobacterium avium by hospital hot water systems. JAMA 1988;260:1599-601.

87. Prince DS, Peterson DD, Steiner RM, Gottlieb JE, Scott R, Israel HL, et al. Infection with Mycobacterium avium complex in patients without predisposing conditions. N Engl J Med 1989;321:863-8.

88. Hartman TE, Swensen SJ, Williams DE. Mycobacterium avium intracellulare complex: evaluation with CT. Radiology 1993;187:23-6.

89. Swensen SJ, Hartman TE, Williams DE. Computed tomographic diagnosis of Mycobacterium avium intracellulare complex in patients with bronchiectasis. Chest 1994;105:49-52.

90. Case Records of the Massachusetts General Hospital. Weekly clinicopathological exercises. Case 6-1996. A 40year-old man with a cough, increasing dyspnea, and bilateral nodular lung opacities. N Engl J Med 1996;334:521-6.

91. Embil J, Warren P, Yakrus M, Stark R, Corne S, Forrest D, et al. Pulmonary illness associated with exposure to Mycobacterium avium complex in hot tub water. Hypersensitivity pneumonitis or infection? Chest 1997;111:813-6.

92. Kahana LM, Kay JM, Yakrus MA, Waserman S. Mycobacterium avium complex infection in an immunocompetent young adult related to hot tub exposure. Chest 1997;111: $242-5$.

93. American Thoracic Society. Diagnosis and treatment of disease caused by nontuberculous mycobacteria. Am J Respir Crit Care Med 1997;156:S1-25.

94. Fujita J, Ohtsuki Y, Suemitsu I, Shigeto E, Yamadori I, Obayashi Y, et al. Pathological and radiological changes in resected lung specimens in Mycobacterium avium intracellulare complex disease. Eur Respir J 1999;13:535-40.

95. Huang JH, Kao PN, Adi V, Ruoss SJ. Mycobacterium aviumintracellulare pulmonary infection in HIV-negative patients without pre-existing lung disease: diagnostic and management limitations. Chest 1999;115:1033-40.

96. Wright JL, Pare PD, Hammond M, Donevan RE. Eosinophilic pneumonia and atypical mycobacterial infection. Am Rev Respir Dis 1983;127:497-9.

97. Culiner MM. The right middle lobe syndrome: a nonobstructive complex. Dis Chest 1966;50:57-66.

98. Bertelsen S, Christensen ES, Aasted A, Sparup J. Isolated middle lobe atelectasis: aetiology, pathogenesis, and treatment of the so-called middle lobe syndrome. Thorax 1980; 35:449-52.

99. Eskenasy A, Eana-Iorgulescu L. Pathology of the middle lobe syndrome: a histopathological and pathogenetic analysis of sixty surgically-cured cases. Rev Roum Med 1982;20: 73-80.

100. Wagner RB, Johnston MR. Middle lobe syndrome. Ann Thorac Surg 1983;35:679-86.

101. Reich J, Johnson R. Mycobacterium avium complex pulmonary disease presenting as an isolated lingular or middle lobe pattern. The Lady Windermere syndrome. Chest 1992; 101:1605-9.

102. Springer C, Avital A, Noviski N, Maayan C, Ariel I, Mogle P, et al. Role of infection in the middle lobe syndrome in asthma. Arch Dis Child 1992;67:592-4.

103. Kwon KY, Myers JL, Swensen SJ, Colby TV. Middle lobe syndrome: a clinicopathological study of 21 patients. Hum Pathol 1995;26:302-7. 